\title{
Vibrios en los sistemas marinos costeros
}

\author{
Vibrios in the marine coastal systems \\ Yanett Leyton $^{1}$ y Carlos Riquelme ${ }^{2 *}$ \\ 'Programa Doctorado en Ciencias Aplicadas, mención Sistemas Marinos Costeros, Facultad de Recursos del Mar, \\ Universidad de Antofagasta, Casilla 170, Antofagasta, Chile \\ ${ }^{2}$ Laboratorio de Ecología Microbiana, Departamento de Acuicultura, Facultad de Recursos del Mar, \\ Universidad de Antofagasta, Casilla 170, Antofagasta, Chile \\ criquelme@uantof.cl
}

\begin{abstract}
In the last years, the studies about vibrios in marine coastal systems have been increased. This literature revision has been made concerning to the themes of the vibrios and the interaction with bacterioplankton, phytoplankton and upper organisms. Antecedents provided permit to conclude that vibrios are a group of bacteria, with multiple interactions with the other components of the marine ecosystem. Several vibrios species are indispensable to marine organism's survival and subsistence, while others are pathogens. Considering that most of the collected information is related to research of interactions in laboratory conditions and/or quantitative analysis in the water column, future investigations should be focused to understand the molecular mechanisms of the ecology of the vibrios in the marine, pelagic and benthic ecosystem. Besides, to search the potential utilization of vibrios that are beneficial in the interaction with other marine organisms, elucidating the involved molecules and their action mechanism.
\end{abstract}

Key words: Interaction, bacteria, microalgae
Resumen.- En los últimos años se ha incrementado el interés sobre la investigación de vibrios en los sistemas marinos costeros. El presente estudio es una revisión actualizada de la literatura concerniente a la temática de las bacterias vibrios y su interacción con el bacterioplancton, fitoplancton y organismos superiores. Los antecedentes proporcionados permiten concluir que los vibrios son un grupo de bacterias con múltiples interacciones con los demás componentes del ecosistema marino. Varias especies pertenecientes de vibrios son indispensables para la supervivencia y subsistencia de numerosos organismos marinos, mientras que otros son patógenos. Considerando que la mayoría de la información encontrada se relaciona con investigación de interacciones en condiciones de laboratorio y/o análisis cuantitativo en la columna de agua, futuras investigaciones debieran ser dirigidas a comprender los mecanismos moleculares de la ecología de los vibrios en el ecosistema marino, pelágico y bentónico. Además, de buscar la potencial utilización de vibrios que son benéficos en la interacción con otros organismos marinos, elucidando las moléculas involucradas y sus mecanismos de acción.

Palabras clave: Interacción, bacteria, microalga

\section{Distribución y diversidad de vibrios}

Los vibrios fueron uno de los primeros grupos bacterianos en ser reconocidos y descritos taxonómicamente en la naturaleza (Pacini 1854); se clasifican en la familia Vibrionaceae abarcando diversos grupos de bacterias marinas heterótrofas; son gama proteo bacterias, Gram negativa, oxidasa positivos, mesófilos, generalmente móviles por medio de un simple flagelo polar (Thompson et al. 2004a). Toleran un amplio rango de salinidades, el óptimo requerimiento de $\mathrm{NaCl}$ es de $\sim 2,0$ a 2,5\% (peso/ volumen), algunas especies (halófilas) requieren al menos una concentración del $0,5 \%$ de $\mathrm{NaCl}$ en el medio para crecer, mientras que especies no halófilas como Vibrio cholerae, Vibrio mimicus o Vibrio hispanicus, pueden crecen con concentraciones mínimas de sal (Gómez-Gil et al. 2004). La presencia de altas concentraciones de

\footnotetext{
* Autor invitado
}

nutrientes orgánicos o cationes divalentes pueden compensar la falta de $\mathrm{Na}^{+}$(Urakawa \& Rivera 2006). Naturalmente habitan ambientes marinos y de agua dulce en formas de vida planctónica en la columna de agua (Worden et al. 2006), bentónica desarrollando biopelículas en sedimentos, zooplancton (Heidelberg et al. 2002) y en el tracto gastrointestinal de organismos marinos (Watnick et al. 2001). Diversos estudios han demostrado que los vibrios se encuentran en altas densidades en el ecosistema marino (Fig. 1, Tabla 1) y han sido extensamente estudiados en los sistemas costeros por su importancia medioambiental e incidencia en la extracción de moluscos (Thompson \& Polz 2006). La distribución y dinámica de estas poblaciones están influenciadas por gradientes medioambientales como temperatura, salinidad, disponibilidad de nutrientes y factores biológicos como, depredación y abundancia de dinoflagelados y hospedadores (Thompson \& Polz 2006). $\mathrm{Al}$ respecto, diversos estudios estuarinos y costeros de 


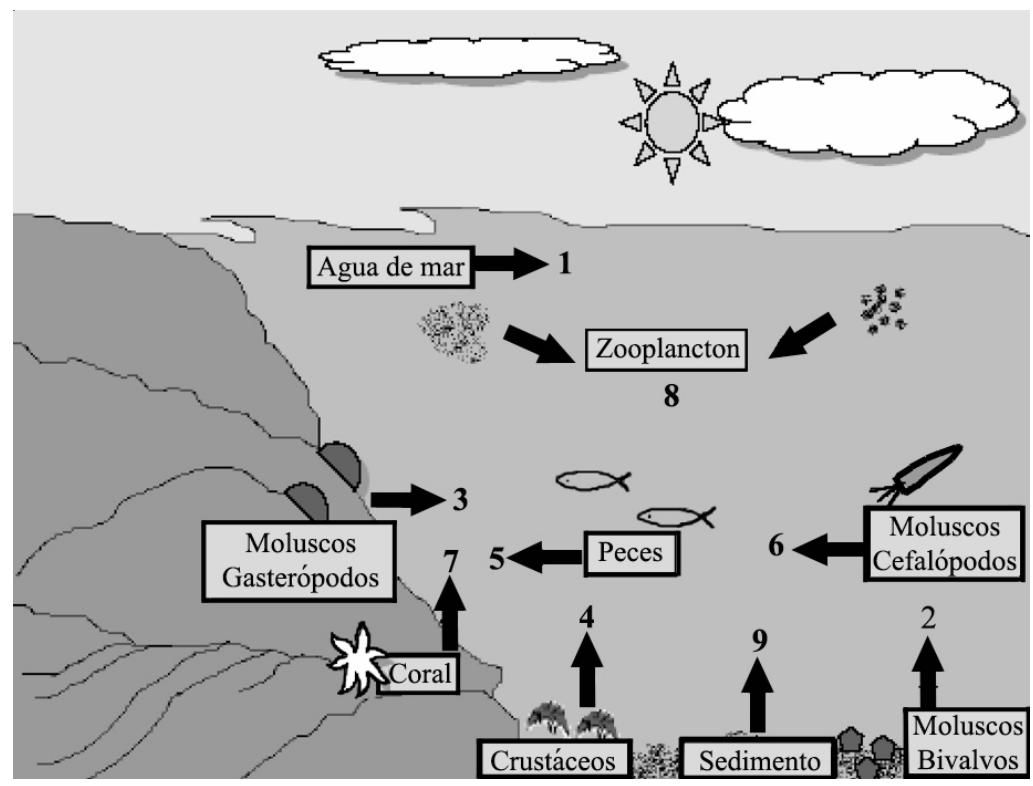

Figura 1

Representación grafica de las interacciones de vibrios en diferentes compartimentos del ecosistema costero

Schedule of interactions between vibrios in different compartments of the coastal ecosystem

diferentes partes del mundo han demostrado que la temperatura y salinidad juegan funciones importantes en la ocurrencia del $V$. cholerae (Jiang 2001). En general, los vibrios tienden a ser más comunes en aguas cálidas, en particular cuando las temperaturas exceden $17^{\circ} \mathrm{C}$ (Thompson et al. 2004), no obstante, Urakawa \& Rivera (2006) postulan que en aguas tropicales y subtropicales la variación de poblaciones de vibrios es baja. Poco es el conocimiento que se tiene sobre la distribución, abundancia, supervivencia y función ecológica de especies de vibrios en el sedimento marino (Urakawa \& Rivera 2006). Se ha sugerido que la ocurrencia estacional de vibrios mesófilos como Vibrio parahaemolyticus y $V$. coralliilyticus se puede deber a una 'hibernación' en sedimentos o en asociación con la fauna marina (BenHaim et al. 2003), por lo que no es sorprendente que estas bacterias posean un gran repertorio de proteínas con enorme especificidad de sustratos, los cuales le permiten realizar diferentes funciones catabólicas para responder eficientemente a los constantes cambios en los ecosistemas (Connell et al. 1998). El tracto digestivo de organismos marinos posee mayor disponibilidad de materia orgánica que el agua de mar, transformándose en un ambiente apropiado para vibrios, aunque en este micro ambiente están expuestos a un $\mathrm{pH}$ bajo, secreción de ácido bilico y a condiciones micro o anaeróbicas (Urakawa \& Rivera 2006). Lo anterior permite el desarrollo de biopelículas las cuales son comunidades microbianas que forman una matriz con sustancias extracelulares producidas por ellas (Maric \& Vranes 2007); esta formación de biopelículas puede constituir una estrategia para sobrevivir en períodos de escasez de nutrientes (Lipp et al. 2002), protegerse contra cambios ambientales (Eboigbodin et al. 2007), atrapar y absorber nutrientes, resistir a antibióticos y establecer interacciones favorables con otras bacterias (Thompson et al. 2004).

Las especies de Vibrio varían considerablemente en patogenicidad y aún están indefinidas las causas de su aparición y epidemiología. Esto es relevante debido a que ocasionan numerosos episodios patológicos, casos de mortalidad y grandes pérdidas económicas y alteraciones sociales en la población dedicada a industrias extractivas y procesadoras de productos del mar (Hernández et al. 2005). Los vibrios en la naturaleza pueden estar en un estado inactivo o no ser capaces de crecer en los medios selectivos empleados (Colwell \& Grimes 2000), no obstante, se ha evidenciado que las bacterias en estado de viables no cultivables (VBNC) pueden también causar enfermedades (Colwell 2000). Rosenberg \& Ben-Haim (2002) postulan que se observan diferencias entre las bacterias VBNC (Bacterias Viables no Cultivables) y las bacterias viables cultivables como reducción del tamaño de la célula, aumento del grosor de la pared celular, disminución de la cantidad de RNA, DNA y formación de biopelículas. Por otro lado, aunque la costa difiere significativamente del océano abierto con respecto a los rangos de producción primaria e influencia terrestre, la 
Tabla 1

Concentración de Vibrio aislados desde muestras de agua de mar y diferentes organismos marinos, citadas en referencias bibliográficas

Concentration of Vibrio isolated from samples of seawater and various marine organisms cited in literature

\begin{tabular}{|c|c|c|c|}
\hline $\mathrm{N}^{\mathrm{o}}$ & Agua / Organismo & Especie de Vibrio & Concentración y referencia \\
\hline \multirow[t]{11}{*}{1} & Agua de mar & Vibrio spp. & $10^{2} \mathrm{CFU} \mathrm{mL}^{-1}$ (Pujalte et al. 1999) \\
\hline & & Vibrio spp. & $1 \times 10^{2}-7 \times 10^{4}$ cél. $L^{-1}$ (Eilers et al. 2006$)$ \\
\hline & & Vibrio spp. & $9,7 \times 10^{5}$ cél. $\mathrm{mL}^{-1}$ (Eilers et al. 2000 ) \\
\hline & & V. vulnificus & $10^{4}$ cél. $\mathrm{L}^{-1}$ (Eilers et al. 2006) \\
\hline & & V. cholerae & $10^{4}$ cél. $\mathrm{L}^{-1}$ (Eilers et al. 2006) \\
\hline & & V. splendidus & $10^{2} \mathrm{CFU} \mathrm{mL} \mathrm{mL}^{-1}$ (Pujalte et al. 1999) \\
\hline & & $V$. harveyi & 26 a $58 \mathrm{CFU} \mathrm{mL} \mathrm{mL}^{-1}$ (Makemson et al. 1992) \\
\hline & & V. harveyi & 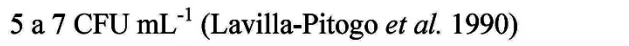 \\
\hline & Agua de $\operatorname{mar}\left(16^{\circ} \mathrm{C}\right)$ & V. parahaemolyticus & 4 cél. $100 \mathrm{~mL}^{-1}$ (DePaola et al. 1990$)$ \\
\hline & $\begin{array}{l}\text { Agua de mar } \\
\text { (cultivo peces) }\end{array}$ & Vibrio spp. & $10^{2}$ cél. $\mathrm{mL}^{-1}$ (Pujalte et al. 1999) \\
\hline & $\begin{array}{l}\text { Agua de mar } \\
\text { (cultivo rotíferos) }\end{array}$ & V. rotiferianus & $1,7 \times 10^{5} \mathrm{CFU} \mathrm{mL}^{-1}$ (Suantika 2001) \\
\hline \multirow[t]{6}{*}{2} & Crassostrea gigas & $\begin{array}{l}\text { Vibrio spp. } \\
\text { V.parahaemolyticu }\end{array}$ & $\begin{array}{l}3,2 \times 10^{2} \text { y } 1,9 \times 10^{3} \mathrm{CFU} \mathrm{ml}^{-1} \text { (Estes et al. 2004) } \\
8,4 \times 10^{5}-3,4 \times 10^{7} \mathrm{CFU} \mathrm{g}^{-1}(\text { Calik et al. 2002) }\end{array}$ \\
\hline & Ostras & V. splendidus & $10^{5} \mathrm{CFU} \mathrm{g}^{-1}$ (Pujalte et al. 1999) \\
\hline & & V. parahaemolyticus & $10^{3} \mathrm{CFU} \mathrm{g}^{-1}$ (Kaysner \& DePaola 2000) \\
\hline & & V. parahaemolyticus & $10^{3} \mathrm{CFU} \mathrm{g}^{-1}$ (DePaola et al. 2000) \\
\hline & Ostión & V. vulnificus & $10^{5} \mathrm{CFU} \mathrm{g}^{-1}$ (Cai et al. 2007) \\
\hline & & V.parahaemolyticus & $10^{4} \mathrm{CFU} \mathrm{g}^{-1}$ (Colwell 1996) \\
\hline \multirow[t]{6}{*}{3} & Turbo cornutus & V. halioticoli & $1,7 \times 10^{5} \mathrm{CFU} \mathrm{g}^{-1}$ (Sawabe et al. 2003) \\
\hline & Haliotis diversicolor supertexta & V.parahaemolyticus & $3,5 \times 10^{5} \mathrm{CFU} \mathrm{mL}^{-1}$ (Cai et al. 2007) \\
\hline & Haliotis discus (digestivo) & V. halioticoli & $2,6 \times 10^{6}$ a $9,9 \times 10^{8} \mathrm{CFU} \mathrm{g}^{-1}$ (Sawabe et al. 1995) \\
\hline & Haliotis midae (digestivo) & V. halioticoli & $3,7 \times 10^{6} \mathrm{CFU} \mathrm{g}^{-1}$ (Sawabe et al. 2006) \\
\hline & Haliotis tuberculata & V. gallicus & $3,0 \times 10^{6} \mathrm{CFU} \mathrm{g}^{-1}$ (Sawabe et al. 2006) \\
\hline & Haliotis laevigata (digestivo) & Vibrio spp & $9,4 \times 10^{6} \mathrm{CFU} \mathrm{g}^{-1}$ (Sawabe et al. 2006) \\
\hline \multirow[t]{5}{*}{4} & Litopenaeus vannamei & Vibrio spp & $10^{5}$ y $10^{4} \mathrm{CFU} \mathrm{g}^{-1}$ (Gomez-Gil et al. 1998) \\
\hline & & Vibrio spp & $10^{9} \mathrm{CFU} \mathrm{g}^{-1}$ (Moss et al. 2000) \\
\hline & Penaeus merguiensis & V. logei & $10^{4}$ y $10^{5} \mathrm{CFU} \mathrm{g}^{-1}$ (Oxley et al. 2002) \\
\hline & Penaeus monodon & A. pelagius & $10^{4} \mathrm{CFU} \mathrm{mL}^{-1}$ (Aguirre-Guzman et al. 2003) \\
\hline & Penaeus monodon & $V \cdot$ parahaemolyticus & $1 \times 10^{5}$ CFU peneido ${ }^{-1}$ (Sudheesh \& Xu 2001) \\
\hline 5 & $\begin{array}{l}\text { Anguilla japonica } \\
\text { Plecoglossus altivelis }\end{array}$ & $\begin{array}{l}\text { V. vulnificus } \\
\text { V. cholerae }\end{array}$ & $\begin{array}{l}9,4 \times 10^{3} \text { a } 2,3 \times 10^{5} \mathrm{CFU} \text { anguila }{ }^{-1} \text { (Tison et al. } 1982 \text { ) } \\
1,26 \times 10^{4} \text { y } 1,26 \times 10^{2} \text { cél. } \mathrm{mL}^{-1} \text { (Yamanoi et al. } 1980 \text { ) }\end{array}$ \\
\hline 6 & Sepiolla sp. & Vibrio spp. & $10^{11}$ cél. órgano ${ }^{-1}$ (Nishiguchi 2000) \\
\hline 7 & Oculina patagonica & V. shiloi & $10^{8}$ a $10^{9}$ cél. $\left(\mathrm{cm}^{3}\right)^{-1}$ (Rosenberg \& Koren 2006) \\
\hline 8 & Zooplancton & Vibrio spp. & $4,3 \times 10^{6}$ cél. $\left(\mathrm{mm}^{2}\right)^{-1}$ (Heidelberg et al. 2002) \\
\hline \multirow[t]{2}{*}{9} & Sedimento & Vibrio spp. & $3,0 \times 10^{3} \mathrm{CFU} \mathrm{g}^{-1}$ (Maeda et al. 2003) \\
\hline & & V. harveyi & $10^{3} \mathrm{CFU} \mathrm{g}^{-1}$ (Ramesh et al. 1989) \\
\hline
\end{tabular}


secuencia del 16S rRNA de vibrios aislados desde el océano abierto son filogenéticamente similares a las secuencias de medio ambientes costeros (Radjasa et al. 2001). A pesar de esto los vibrios son el grupo mayormente cultivable de bacterias heterótrofas, especialmente de aguas costeras y, la proporción de recuento total en placas varía de acuerdo a los métodos de muestreo, áreas geográficas, estacionalidad y medios de cultivos diferenciales (Austin et al. 1979). Actualmente se están desarrollando nuevos métodos para identificar la patogenicidad, ecología y distribución de vibrios, además, de evaluar aquellas especies que evaden los métodos convencionales de cultivo (Eilers et al. 2007).

En el ecosistema marino los vibrios juegan funciones importantes como biodegradación de la materia orgánica y regeneración de nutrientes (Cavallo \& Stabili 2004), además pueden actuar como patógenos de organismos acuáticos de importancia comercial, o bien afectar al hombre (Thompson et al. 2004). Existe una gran diversidad de vibrios reconociéndose casi 74 especies descritas dentro de este grupo (Thompson et al. 2004), algunas de las cuales se ha elucidado su función ecológica en la naturaleza. De acuerdo al manual de Bergey, la familia Vibrionaceae comprende 8 géneros: Vibrio $(65$ especies), Allomonas (1 especie), Catenococcus (1 especie), Enterovibrio (2 especies), Grimontia (1 especie), Listonella (2 especies), Photobacterium (8 especies) y Salinivibrio (1 especie) (Thompson \& Swings 2006). Urbanczyk et al. (2007) proponen un noveno género en el que reclasifican a las especies, Vibrio fischeri, $V$. logei, V. salmonicida y $V$. wodanis, las cuales estaban estrechamente relacionadas formando un clado dentro de la familia Vibrionaceae. Los autores indican que las cuatro especies representan un linaje dentro de Vibrionaceae que es distinta de otros géneros. Aliivibrio se compone de cuatro especies: Aliivibrio fischeri comb. nov., Aliivibrio logei comb. nov., Aliivibrio salmonicida comb. nov. y Aliivibrio wodanis comb. nov. Thompson et al. (2004) proponen tres nuevas familias además de Vibrionaceae basándose en el 16S rRNA, de la secuencia de los genes recA y rpoA y datos fenotípicos, estos son: Enterovibrionaceae (comprendido por los géneros Enterovibrio y Grimnontia), Photobacteriaceae (comprendido por el género Protobacterium) y Salinivibrionaceae (comprendido por el género Salinivibrio). El propósito de considerar sólo al género Vibrio dentro de la familia Vibrionaceae se debe a diferentes análisis genotípicos y moleculares que muestran a vibrios como altamente heterogéneos (Thompson et al. 2005).

Es importante estudiar a los vibrios que actúan de forma deletérea sobre organismos de importancia comercial, debido a las consecuencias económicas que este produce (Bergh et al. 2001) y descubrir los factores que ocasionan este accionar es aún una tarea pendiente. El objetivo de esta revisión es resumir la información disponible sobre vibrios y su interacción con diferentes componentes de la cadena trófica marina.

\section{Vibrios y bacterioplancton}

La aparición del concepto 'Anillo microbiano' postulado por Azam et al. (1983) revolucionó la investigación microbiológica de ecosistemas acuáticos, ya que, fue un impulso para ampliar el conocimiento de que las bacterias no sólo actúan como descomponedoras de la materia orgánica sino que además tienen una importante función en la base de la cadena trófica. En la actualidad cada vez más se investiga sobre los aspectos benéficos o antagónicos de la interacción de algunas especies bacterianas y los demás componentes del ciclo microbiano. Los vibrios han sido identificados como mediadores significativos de interacciones antagonistas entre bacterias marinas (Long \& Azam 2001). Las bacterias antagónicas son capaces de actuar sobre un amplio rango de los componentes del plancton, incluyendo algunas bacterias, diatomeas y dinoflagelados (Yoshinaga et al. 1997) algunas de las cuales se han estado usando en organismos acuáticos para prevenir altas mortalidades larvales (Gómez-Gil et al. 2000) (Tabla 2A). Es importante considerar que la mayoría de los vibrios patógenos son resistentes a antibióticos como oxitetraciclina, norfloxacina y ciprofloxacina debido al uso frecuente de éstos en los sistemas de cultivo. Por ejemplo, recientemente se ha demostrado una amplia resistencia de vibrios a los antibióticos comúnmente usados en cultivos de camarón (Molina et al. 2002). Lo anterior plantea la urgente necesidad de buscar alternativas al uso de antibióticos para el control de patógenos. Una posibilidad es el uso de vibrios nativos no patógenos como potenciales probióticos y/o simbiontes actuando como agentes de biocontrol en organismos de cultivos y así disminuir el uso de antibióticos y reducir las descargas de efluentes tóxico al medio ambientes (Jayasree et al. 2006, Riquelme et al. 2001). Estudios recientes han comprobado que el uso de mezclas de cepas probióticas reduce la presencia de vibrios patógenos en los sistemas acuícolas (Sotomayor \& Balcázar 2003). Estos antecedentes evidencian la posibilidad que, en ecosistemas acuáticos, las interacciones bacteria-bacteria podrían ser específicas permitiendo regular la proliferación de algunas especies bacterianas.

\section{Vibrios y fitoplancton}

El crecimiento microalgal en el ecosistema marino depende de la luz, temperatura y nutrientes, su interacción 
Tabla 2

Interacciones de vibrios con otros organismos de la cadena trófica marina. A: Interacción positiva; B: Interacción negativa

Interactions of vibrios with other organisms of the marine food chain. A: Positive interaction; B: Negative interaction

\begin{tabular}{l} 
A Especie de Vibrio \\
\hline Vibrio alginolyticus \\
V. alginolyticus (C7b) \\
Vibrio sp. (C33) \\
Vibrio sp. \\
\\
Vibrio sp. (strain NM10) \\
A. fischeri \\
Alivibrio logei \\
V. rotiferianus \\
V. halioticoli \\
V. fluvialis \\
V. mediterranei \\
Listonella anguillarum \\
(anteriormente V. anguillarum) \\
Vibrio spp.
\end{tabular}

Organismos beneficiados y referencia

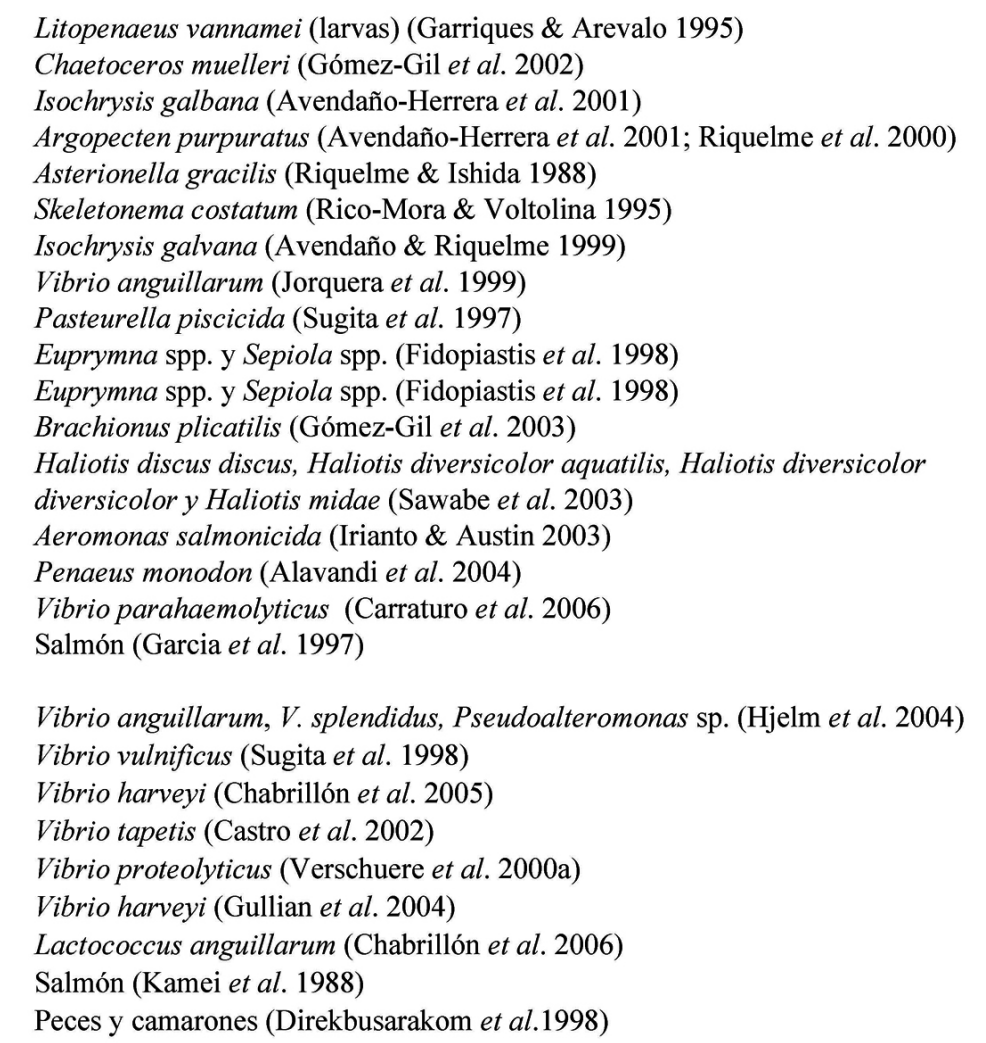

B Especie de Vibrio

Organismos afectados y referencia

\begin{tabular}{ll}
\hline Listonella anguillarum & Scophthalmus maximus (Angulo et al. 1994) \\
& Crassostrea virginica (larvas) (Brown 1981) \\
& Mercenaria mercenaria (larvas) (DiSalvo et al. 1978) \\
& Ostrea edulis (larvas) (Lodeiros et al. 1987) \\
& Argopecten purpuratus (larvas) (Riquelme et al. 1995) \\
& Crassostrea gigas (juvenil y adulto) (Grischowski \& Liston 1974) \\
& Oncorhynchus spp., S. salar, S. maximus, D. labrax, Morone saxatilis, \\
& Anguilla japonica y A. anguilla, P. altivelis, Gadus morhua, S. aurata (Toranzo \\
& \& Barja 1990, 1993; Actis et al. 1999; Thompson \& Swings 2006). \\
& Tetraselmis suecica (Olsen et al. 2000) \\
& Salmo salar (Austin \& Austin 1999) \\
& Salmo salar (Toranzo et al. 2005) \\
& \\
A. salmonicida & Tetraselmis suecica (Olsen et al. 2000) \\
& Anguilla japonica (Tison et al. 1982) \\
& Chlorella sp. (Tendencia \& De la Pena 2003) \\
V. vulnificus & Sulculus diversicolor supratexta (Austin \& Zhang 2006) \\
Solea senegalensis (Zorrilla et al. 2003) \\
Holothuria scabra (Austin \& Zhang 2006) \\
Centropomus undecimalis (Austin \& Austin 1999) \\
Penaeus monodon (larvas) (Ransom et al. 1984)
\end{tabular}


Cont. Tabla 2

V. splendidus

A. fischeri

V. alginolyticus

V. coralliilyticus

Aliivibrio logei

V. parahaemolyticus

V. pectenicida

$V$. pelagius

V. campbellii

$V$. nereis

V. proteolyticus

$V$. tapetis

V. tubiashii

V. shiloi

$V$. mediterranei

V. ordallii

V. cholerae (non-OI)

V. furnissii

V. mimicus

$V$. ichthyoenteri sp. nov.

Moritella marina

Moritella viscosa

(anteriormente $V$. viscosus)

Photobacterium damselae

Shewanella putrefaciens

$V$. nigripulchritudo

$V$. brasiliensis

V. ezurae

V. fortis
Scophthalmus maximus (Angulo et al. 1994)

Oculina patagonica (Koren \& Rosenberg 2006 )

Crassostrea gigas (Le Roux et al. 2004)

Pecten maximus (Lambert et al. 1999)

Penaeus monodon (Lavilla-Pitogo \& Dela Pena 1998)

Skeletonema costatum (Naviner et al. 1999)

Scophthhalmus maximus (juvenil) (Lamas et al. 1990)

Sparus aurata (Balebona et al. 1998)

Tetraselmis suecica (Olsen et al. 2000)

Sparus aurata (Austin \& Austin 1999, Akayli et al. 2008)

Ostrea edulis (larvas) (Lodeiros et al. 1987)

Mercenaria mercenária (larvas) (Tubiash et al. 1970)

Crassostrea virginica (larvas) (Tubiash et al. 1970)

Argopecten ventricosus (larvas) (Luna-Gonzales et al. 2002)

Nodipecten subnodosus (larvas) (Luna-Gonzales et al. 2002)

Atrina maura (larvas) (Luna-Gonzales et al. 2002)

Crassostrea gigas (larvas) (Luna-Gonzales et al. 2002)

Oncorhynchus mykiss (Austin et al. 2005)

Nodipecten nodosu (larvas) (Ben-Haim et al. 2003)

Pocillopora damicornis (Ben-Haim et al. 2003)

Crassostrea gigas (larvas) (Ben-Haim et al. 2003)

Penaeus monodon (Lavilla-Pitogo et al. 1998)

Salmo salar (Benediktsdóttir et al. 1998)

Haliotis diversicolor supertexta (Cai et al. 2007)

Solea senegalensis (Zorrilla et al. 2003)

Oreochromis niloticus (Balfry et al. 1997)

Penaeus monodom (Sudheesh \& Xu 2001)

Pecten maximus (larvas) (Lambert et al. 2001)

Penaeus japonicus (Takahashi et al. 1998)

Litopenaeus stylirostris (Goarant et al. 2000)

Scophthalmus maximus (juvenil) (Angulo et al. 1992)

Sparus aurata (Balebona et al. 1998)

Sparus aurata (Balebona et al. 1998)

Artemia sp. (Verschuere et al. 2000b)

Ruditapes philippinarum (larvas) (Borrego et al. 1996)

Ruditapes philippinarum (juvenil/adultos) (Paillard \& Maes 1995)

Ruditapes decussatus (Novoa et al. 1998)

Crassostrea gigas (larvas) (Takahashi et al. 2000)

Crassostrea virginica (larvas) (Tubiash et al. 1965)

Ostrea edulis (larvas) (Lodeiros et al. 1987)

Oculina patagonica (Kushmaro et al. 2001)

Pocillopora damicornis (Ben-Haim \& Rosenberg 2002)

Oncorhynchus kisutch (Ransom et al. 1984)

Oncorhynchus rhoddurus (Thompson \& Swings 2006)

Salmónidos (Toranzo et al. 2005)

Plecoglossus altivelis (Austin \& Austin 1999)

Carassius auratus (Reddacliff et al. 1993)

Anguila anguila (Esteve 1995)

Cherax quadricarinatus (Eaves \& Kelterer 1994)

Paralichthys olivaceus (Ishimaru et al. 1996)

Salmo salar (Benediktsdóttir et al. 1998)

Salmo salar (Benediktsdóttir et al. 2000)

Salmo salar (Toranzo et al. 2005)

Chromis punctipinnis (Austin \& Austin 1999)

Scophthalmus maximus (Fouz et al. 1991)

Siganus rivulatus, rabbitfish (Saeed et al. 1987)

Litopenaeus stylirostris (Reynaud et al. 2008)

Oncorhynchus mykiss (Austin et al. 2005)

Oncorhynchus mykiss (Austin et al. 2005)

Oncorhynchus mykiss (Austin et al. 2005) 
Cont. Tabla 2

\section{V. kanaloaei \\ V. neptunius \\ V. rotiferianus \\ V. tubiashii \\ V. carcharine \\ Vibrio sp.}

Photobacterium damselae subsp. damselae

Vibrio hollisae

\author{
Oncorhynchus mykiss (Austin et al. 2005) \\ Oncorhynchus mykiss (Austin et al. 2005) \\ Oncorhynchus mykiss (Austin et al. 2005) \\ Oncorhynchus mykiss (Austin et al. 2005) \\ Haliotus tuberculata (Enger et al. 1991) \\ Sparus aurata (Zorrilla et al. 2003) \\ Skeletonema costatum (Naviner et al. 1999) \\ Tetraselmis suecica (Olsen et al. 2000) \\ Paralichthys olivaceus (larva) (Muroga et al. 1990) \\ Crassostrea virginica (larvas) (Elston et al. 1981) \\ Crassostrea virginica (juveniles y adultos) (Elston et al. 1982) \\ Mercenaria mercenaria (larvas) (Brown \& Tettelbach 1988) \\ Mercenaria mercenaria (juveniles y adultos) (Elston et al. 1982) \\ Argopecten irradians (larvas) (Tubiash et al. 1965) \\ Teredo navalis (larvas) (Tubiash et al. 1965) \\ Crassostrea gigas (larvas) (Garland et al. 1983) \\ Ostrea edulis (larvas) (Jeffries 1982) \\ Ostrea edulis (juveniles y adultos) (Elston et al. 1982) \\ Chromis punctipinnis (Thompson \& Swings 2006)
}

Seriola dumerili (Ji et al. 2008) con los vibrios se puede deber a que estos aprovechan para su proliferación el decaimiento de los afloramientos fitoplanctónicos o por una interacción positiva bacteriamicroalga mediante el uso de algunos exudados como vitaminas y factores de crecimiento (Haines \& Guillard 1974). Por otro lado, el crecimiento microalgal se puede ver afectado negativamente al actuar la bacteria como algicida o inhibidor del crecimiento mediante la excreción de productos extracelulares (Riquelme \& AvendañoHerrera 2003), el que genera un micro ambiente enriquecido de materia orgánica disuelta lábil, que puede ser explotada por otra población bacteriana (Thompson $\&$ Polz 2006). Debido a estos efectos directos e indirectos del crecimiento microalgal la proliferación de vibrios en el ambiente se puede ver afectada, ya que estos utilizan las sustancias orgánicas derivadas de la microalgas como sustrato de crecimiento (Ohara et al. 1993). Indudablemente que estas interacciones son reciprocas y específicas dependiendo de las condiciones del ecosistema y actuarían como agentes controladores de la sucesión y estructuras de las comunidades en los ecosistemas.

\section{Vibrios probióticos}

Hay vibrios que establecen y mantienen una relación simbiótica positiva con organismos marinos (Urakawa \& Rivera 2006). Una de las relaciones de simbiosis mas estudiadas es la utilización de la quitina del calamar Eupyrmna scolopes, nutriente importante para el
Aliivibrio fischeri (anteriormente $V$. fischeri Thompson \& Swings 2006) quien la utiliza como fuente de carbono (Meibom et al. 2004) y a su vez el calamar aprovecha la bioluminiscencia de las bacterias, en la comunicación, atracción de presas y defensa ante depredadores (Fidopiastis et al. 1998). Vibrio harveyi excreta más de 10 enzimas que degradan la quitina (Suginta et al. 2004) que es un polímero natural ( $N$-acetil-D-glucosamina) y una de las fuentes mas abundantes de amino azucares en el océano (Riemann \& Azam 2002). Investigaciones en camarones silvestres sanos (Penaeus mergulensis) han reportado una alta abundancia de vibrios, sugiriéndose que puede ser el camarón el que influencia y/o selecciona su flora bacteriana (Oxley et al. 2002). Además existen antecedentes que la asociación de vibrios y plancton aumenta la supervivencia de Litopenaeus vannamei indicando que Vibrio y Aeromonas componen hasta el $85 \%$ de la flora bacteriana en el intestino del camarón. Mezclas de cepas probióticas como Vibrio alginolyticus y Vibrio sp. fueron sometidas a una prueba de inhibición in vitro con vibrios patógenos de camarones ( $V$. harveyi, $V$. vulnificus y $V$. parahaemolyticus) para demostrar su efecto antagónico, presentando porcentajes de inhibición mayores al 50\% (Sotomayor \& Balcázar 2003). En un estudio del ostión Argopecten purpuratus en el cual se realizó una búsqueda de potenciales probióticos para contrarrestar al patógeno Vibrio anguillarum (VAR), de un total de 506 aislados bacterianos, se detectó un vibrio con actividad inhibidora del patógeno al usarlo como pre 
tratamiento en larvas de ostión infectadas con el patógeno (Riquelme et al. 1997). En abalón, Sawabe et al. (2003) estiman que Vibrio halioticoli es la especie dominante en el intestino de especies sanas de Haliotis discus discus, $H$. diversicolor aquatilis, $H$. diversicolor diversicolor y $H$. midae representando 40 a $65 \%$ de la comunidad heterótrofa total. Otras interacciones benéficas de vibrios se pueden observar en la Tabla 2A.

A bacterias de la familia Vibrionaceae se les ha atribuido importancia en la remineralización de elementos como carbono $(\mathrm{C})$, nitrógeno $(\mathrm{N})$ y fósforo $(\mathrm{P})$. Los vibrios consumen una amplia gama de sustratos de carbono (Farmer \& Hickman-Brenner 2006); estas complejas macromoléculas orgánicas son degradadas a través de la digestión extracelular. La alta afinidad por sustrato sugiere que el crecimiento de vibrios se debe a una adaptación a altas condiciones de nutrientes tales como ocurre en el digestivo animal o en micro ambientes planctónicos (Thompson \& Polz 2006). También pueden sobrevivir a la inanición de carbono por largos meses (Armada et al. 2003) y el almacenamiento de carbono puede permitir el crecimiento de vibrios en medio ambientes fluctuantes donde los nutrientes pueden ser limitados en diferentes períodos. Durante la respiración anaeróbica, 30 a $50 \%$ de carbono orgánico es usado para la formación de biomasa, mientras que durante la fermentación se excretan productos metabólicos. Estos incluyen ácidos orgánicos y alcoholes que pueden estimular la cadena alimenticia anaeróbica. Por ejemplo, V. halioticoli aislado del sistema digestivo de los abalones Haliotis discus discus, $H$. diversicolor aquatilis, $H$. diversicolor diversicolor y $H$. midae, fermenta los polisacáridos algales, produciendo hasta un $68 \mathrm{mM}$ de ácido acético y fórmico como principales productos de fermentación de alginato, por lo que se sugiere que la abundancia de poblaciones de V. halioticoli en el intestino de abalón puede ser importante para la conversión de alginato a ácido acético lo que contribuiría a la nutrición del hospedador (Sawabe et al. 2003). Los vibrios pueden tener una contribución importante en la cadena trófica debido a que se demostró que estos pueden producir ácidos grasos poliinsaturados (Nichols 2003), los cuales son nutrientes esenciales para muchos organismos marinos. Aunque la producción de ácidos grasos poli insaturados, PUFAs, mayormente se ha caracterizado a partir de microalgas (Nichols 2003), es interesante encontrarlas en bacterias ya que enfatiza el importante papel que pueden cumplir estas bacterias en la cadena trófica marina. Otros estudios han sugerido que vibrios de distintas profundidades son especializados o metabólicamente más restrictivos con respecto a la utilización del carbono, mientras que los vibrios superficiales tienen diversas actividades metabólicas, incluyendo la habilidad de degradar polímeros lábiles (ejemplo, almidón, caseína) o utilizar mas componentes refractarios (ejemplo, agar) (Simidu \& Tsukamoto 1985). Por ejemplo, Photobacterium profundum tiene un crecimiento óptimo a 2,000 atmósferas (Nogi et al. 1998); se estima que la producción de PUFAs ayudaría a mantener el fluido a través de la membrana bajo altas presiones y bajas temperaturas (Allen et al. 1999).

Los sistemas marinos se han conocido por tener hábitats limitados de nitrógeno mientras que la atmósfera de la tierra representa el mayor reservorio de nitrógeno. Los vibrios son conocidos por participar en muchas de las vías de reducción del nitrógeno como: Fijación del di nitrógeno $\mathrm{N}_{2}$ a nitrógeno $\mathrm{N}$; reducción del nitrato $\left(\mathrm{NO}_{3}^{-}\right)$ a nitrito $\left(\mathrm{NO}_{2}^{-}\right)$o amoniaco $\mathrm{NH}_{4}^{+}$(Herbert 1999). Cuatro especies de vibrios se han conocido por fijar moléculas de nitrógeno (Vibrio diazotrophicus, V. natriegens, V. (Listonella) pelagius y V. cincinnatiensis (Urdaci et al. 1988). La asimilación del Ion nitrato es requerido para el transporte a través de la membrana celular (Chou et al. 1999) y el aumento de temperatura puede facilitar la captación de nitrato por alteración de las propiedades de la membrana (Reay et al. 1999). Por otro lado, los vibrios expresan un número de enzimas extracelulares que participan en la degradación del fósforo; estos juegan una función primordial en el reciclaje del fósforo orgánico e inorgánico disponible para la producción primaria (Thompson \& Polz 2006). La actividad enzimática periplasmática contribuye a la función de los vibrios en la remineralización del fósforo orgánico e inorgánico y pueden servir para enriquecer su medio ambiente de nutrientes que pueden ser utilizados por la producción primaria y otras comunidades heterotróficas. Además, son capaces de hidrolizar polímeros tales como la quitina y pueden crear importantes uniones tróficas entre comunidades del bacterioplancton (Thompson \& Polz 2006). La actividad de la quitinasa puede ser uno de los procesos enzimáticos extracelulares más importantes en el ambiente marino. Este polímero puede ser continuamente remineralizado sustentando la producción primaria en los océanos (Li \& RoseMam 2004).

La información citada entrega antecedentes de que los vibrios son beneficiosos para usarlos como potenciales probióticos en organismos de importancia comercial. Además, muchos investigadores postulan que el uso de bacterias probióticas o una mezcla de ellas tendrían un impacto positivo para la salud de organismos marinos (Olafsen 2001), por lo que estudiar las potencialidades benéficas y mecanismos de acción de los vibrios es una alternativa que debiera considerarse en futuras investigaciones. 


\section{Vibrios patógenos}

El desarrollo de enfermedades es el resultado de la interacción entre patógeno, hospedador y medio ambiente. La infección por Vibrio es uno de los problemas significativos que tienen los cultivos comerciales de peces e invertebrados marinos (Tabla 2B) debido a las mortalidades ocasionadas por los episodios pandémicos, provocando alteraciones sociales en el sector industrial de extracción y procesamiento de recursos marinos, pérdidas en las capturas, con las consecuentes pérdidas económicas. La alta densidad de organismos y nutrientes son característicos en sistemas de acuicultura lo cual facilita la proliferación de vibrios; se ha hipotetizado que las condiciones artificiales del medioambiente en sistemas de cultivo pueden constituirse como reservorio para vibrios patógenos (Ben-Haim et al. 2003). Actualmente, algunos estudios se han enfocado en la relación de la microbiota de aguas contaminadas por bacterias patógenas y sus efectos negativos en organismos de importancia comercial (Urakawa \& Rivera 2006). Varios casos de vibriosis que afectan a bivalvos se han descrito en la literatura. Por ejemplo, se ha reportado que Vibrio anguillarum, $V$. alginolyticus y $V$. splendidus son responsables de ocasionar la muerte de larvas de ostión, debido a un estado de estrés del hospedero que da lugar a una respuesta neuroendocrina que incrementa los niveles de noradrenalina induciendo la liberación de hierro, elemento importante para la reproducción de los vibrios (Platt et al. 1995). En otros bivalvos como almejas, Vibrio tapetis se ha descrito como la bacteria marina responsable de la enfermedad del anillo marrón (BRD) que afecta a Ruditapes philippinarum; en esta enfermedad las bacterias proliferan rápidamente en los tejidos blandos, provocando graves daños y la posterior muerte (Paillard 2004). Al respecto, Flye-Sainte et al. (2007) muestran que almejas gravemente enfermas están sujetas a pérdida de peso en comparación con las no infectadas, lo que indica que BRD induce a un desequilibrio en el balance energético, disminución en la adquisición de energía y frecuencia respiratoria. El método SSP-PCR ha dado lugar a la detección de $V$. tapetis en larvas de almejas enfermas y en reproductores asintomáticos de almejas que más tarde desarrollarán BRD (Waechter et al. 2002). En el cultivo comercial de larvas de almejas $R$. decussatus durante los años 2001 y 2002, en España se observaron dos episodios de mortalidad (62 y 73\%), asociados con infecciones bacterianas de $V$. alginolyticus (en los dos episodios) y $V$. splendidus con $V$. alginolyticus (segundo episodio) causando lesiones histológicas similares que afectaron principalmente el manto, el velo, y el tejido conectivo de los organismos infectados. Según los autores es la primera vez que estas especies bacterianas se han asociado a mortalidades de larvas y juveniles de esta almeja (GómezLeón et al. 2005). Las cepas de $V$. harveyi también se asociaron a mortalidades de abalón Haliotis tuberculata observado en la costa oeste de Francia desde 1997 (Nicolas et al. 2002). Otro Vibrio reportado como patógeno en postlarvas de abalón $H$. diversicolor supertexta es el Vibrio parahaemolyticus (Cai et al. 2007). Una enfermedad que afecta a los corales, causada por vibrios, es el de blanqueamiento de corales que se debe a la interrupción de la simbiosis entre el coral y el dinoflagelado Zooxanthellae, la cual se le ha atribuido a los patógenos Vibrio shilonii (también conocido como $V$. mediterranei), $V$. coralliilyticus (Ben-Haim \& Rosenberg 2002) y V. shiloi (Kushmaro et al. 2001). En peces, un grupo relativamente pequeño de bacterias marinas es responsable de importantes pérdidas económicas en los cultivos de todo el mundo (Toranzo et al. 2005). Los patógenos principales son V. splendidus (Austin \& Austin 1999), Listonella (Vibrio) anguillarum, V. ordalii, Aliivibrio salmonicida (anteriormente V. salmonicida, Thompson \& Swings 2006) y V. vulnificus biotipo 2 (Toranzo et al. 2005). L. anguillarum y V. ordalii causan septicemia hemorrágica en peces. A. salmonicida causa anemias y hemorragia extensa especialmente en órganos internos (Toranzo et al. 2005). Según estudios bacteriológicos, en el salmón del atlántico, las úlceras en la piel u órganos internos (Bruno et al. 1998) se deben a Vibrio viscosus (Lunder et al. 2000) el cual podría ser reclasificado como M. viscosa (Benediktsdóttir et al. 2000). Igualmente, Aliivibrio wodanis (anteriormente $V$. wodanis (Thompson \& Swings 2006, estrechamente relacionado con $V$. logei) (Lunder et al. 2000) se ha aislado de úlceras de peces en Noruega, Islandia y Escocia. Un examen bacteriológico realizado a cultivos de Sparus aurata, en España, entre 1997 y 2000, detectó 25 brotes, cuyo grupo dominante fueron vibrios con un $69 \%$ (Zorrilla et al. 2003). Vibrio harveyi es responsable de enfermedades infecciosas en algunos peces como lenguado, tiburón amarillo (Austin \& Zhang 2006) y también en camarones (Austin \& Zhang 2006). LavillaPitogo et al. (1998) relacionaron masivas pérdidas en cultivos de camarón en Filipinas debido a la presencia de vibrios, reportando mortalidades del $60 \%$ entre 1992 y 1994. Los copépodos, rotíferos y artemias son usados como importantes fuentes nutricionales para el cultivo de muchos organismos acuáticos y existen antecedentes de la asociación de estos organismos con vibrios. Por ejemplo, los vibrios tienen una relación de simbiosis con organismos quitinosos, como los copépodos y numerosos estudios han correlacionado la concentración de copépodos con el número de $V$. parahaemolyticus y $V$. cholerae en el agua de mar (Lipp et al. 2003). Tamplin et al. (1990) postulan que los vibrios utilizan la quitina como 
sustrato y el saco ovígero de los copépodos como un vehículo para la diseminación cuando el copépodo libera los huevos fertilizados al ambiente. También existen antecedentes de la asociación de vibrios y diferentes especies de rotíferos como Vibrio rotiferianus, aislado como bacteria dominante desde cultivos de rotíferos Brachionus plicatilis (Gómez-Gil et al. 2003). Por otro lado, Vibrio hispanicus (Gómez-Gil et al. 2004) y $V$. alginolyticus fueron aislados desde Artemia sp. (Snoussi et al. 2006). La asociación de vibrios patógenos con estos organismos puede tener como consecuencia la transmisión de estas bacterias a larvas que son alimentadas con estos organismos.

Las especies de vibrios patógenos para humanos en la actualidad esta limitada sólo a 12 que son clínicamente significativas $V$. cholerae, $V$. parahaemolyticus, $V$. mimicus, Grimontia (Vibrio) hollisae, V. fluviales, $V$. furnissii, $V$. vulnificus, $V$. alginolyticus, Photobacterium (Vibrio) damselae, V. metschnikovii, V. cincinnatiensis y $V$. harveyi (Nishibuchi 2006). Las infecciones causadas por estos organismos están usualmente asociadas a la ingestión de moluscos contaminados; los síntomas que manifiesta el paciente van desde gastroenteritis, infección a la piel, septicemia, llegando a la mortalidad en el caso de pacientes inmunocomprometidos o con bajas defensas (Rowe-Magnus et al. 2006).

\section{Nueva estrategia para combatir a vibrios patógenos}

En las últimas décadas se ha descubierto que las bacterias son capaces de comunicarse entre sí y que éstas viven en comunidades, donde la conducta individual está coordinada por la comunicación célula-célula por medio de pequeñas señales moleculares denominadas Quórum sensing (QS). Las bacterias usan el QS para supervisar su densidad poblacional, sincronizar su comportamiento y actuar recíprocamente (Van et al. 2007); esto permite que las bacterias sincronicen el comportamiento de grupo como unidades multicelulares (Lenz \& Bassler 2007), para interactuar con el medio ambiente y organismos superiores (Bjarnsholt \& Givshov 2007). Teóricamente, podría ser que el aumento de la densidad de moléculas señales se deba a la limitación por espacio alrededor de la célula o por alteración de la difusión de moléculas auto inductoras que puede aumentar el número celular como lo han discutido Redfield et al. (2002).

Hoy en día para controlar las enfermedades bacterianas en acuicultura se usan antibióticos (Cabello 2006). Al respecto, se ha sugerido la interrupción del QS como una estrategia antibacteriana (Defoirdt et al. 2004); sin embargo, los datos sobre el impacto del QS que detecta la virulencia de patógenos acuáticos son escasos (Defoirdt et al. 2005). Estudios realizados por Defoirdt et al. (2005) indican que la interrupción del QS podría ser una buena estrategia para combatir infecciones por Vibrio harveyi en el cultivo de Artemia franciscana. Estudios han demostrado que, Aliivibrio fischeri y Vibrio logei se encuentran en asociación simbiótica con el calamar Sepiolla spp. y pueden detectar su densidad celular por medio de señales moleculares o feromonas (ejemplo Nacil homoserina lactonas) de tal modo regular la bioluminiscencia (Wolfe et al. 2004). Igualmente, se ha documentado la capacidad de monitorear la densidad celular y regular la expresión de genes de virulencia por medio del QS para los patógeno V. anguillarum (Milton et al. 1997), V. cholerae (Zhu \& Mekalanos 2003), V. harveyi (Lilley \& Bassler 2000), V. parahaemolyticus (Henke \& Bassler 2004) y V. vulnificus (McDougald et al. 2000).

El bloqueo del QS puede atenuar la patogenicidad bacteriana, mas que el crecimiento bacteriano, siendo altamente atractivo, particularmente con respecto a la aparición de bacterias resistentes a antibióticos (Bjarnsholt \& Givskov 2007). Además, los inhibidores de señales podrían ser potencialmente eficaces para impedir la formación de biopelículas (Konaklieva \& Plotkin 2006) y jugar un papel importante en la evolución de las bacterias simbióticas (Taga \& Bassler 2003). Por lo tanto, se debe buscar y aislar cepas bacterianas marinas nativas e inocuas con actividad antagónica sobre especies de vibrios patógenas, con el propósito de utilizarlas como herramientas de control biológico.

\section{Agradecimientos}

Este estudio fue financiado por el proyecto FONDEF MRO7I1006. Los autores agradecen a los evaluadores de esta revista por sus críticas para mejorar la presentación de esta publicación.

\section{Literatura citada}

Actis LA, ME Tolmasky \& JH Crosa. 1999. Vibriosis. En: Woo PTK \& DW Bruno (eds) microorganisms in the environment, pp. 1-6. ASM, Washington, DC.

Colwell RR. 1996. Global climate and infectious diseases: The cholerae paradigm. Science 274(5295): 2025-2031.

Connell TD, DJ Metzger, J Lynch \& JP Folser. 1998. Endochitinase is transported to the extracellular milieu by the eps-encoded general secretory pathway of Vibrio cholerae. Journal of Bacteriology 180(21): 5591-5600.

Defoirdt T, N Boon, P Bossier \& W Verstraete. 2004. Disruption of bacterial quorum sensing: an unexplored strategy to fight infections in aquaculture. Aquaculture 240: 69-88. 
Defoirdt T, P Bossier, P Sorgeloos \& W Verstraete. 2005 The impact of mutations in the quorum sensing systems of Aeromonas hydrophila, Vibrio anguillarum and Vibrio harveyi on their virulence towards gnotobiotically cultured Artemia franciscana. Environmental Microbiology 7(8): 1239-1247.

DePaola A, CA Kaysner, J Bowers \& DW Cook. 2000. Environmental investigations of Vibrio parahaemolyticus in oysters after outbreaks in Washington, Texas, and New York (1997 and 1998). Applied and Environmental Microbiology 66: 4649-4654.

DePaola A, LH Hopkin, JT Peeler, B Wentz \& RM McPhearson. 1990. Incidence of Vibrio parahaemolyticus in US coastal waters and oysters. Applied and Environmental Microbiology 56: 2299-2302.

Direkbusarakom S, M Yoshimizu, Y Ezura, L Ruangpan \& Y Danayadol. 1998. Vibrio spp., the dominant flora in shrimp hatchery against some fish pathogenic viruses. Journal of Marine Biotechnology 6: 266-267.

DiSalvo LH, J Blecka \& R Zebal. 1978. Vibrio anguillarum and larval mortality in a California coastal shellfish hatchery. Applied and Environmental Microbiology 35: 219-221.

Eaves LE \& PJ Ketterer. 1994. Mortalities in red claw crayfish Cherax quadricarinatus associated with systemic Vibrio mimicus infection. Diseases of Aquatic Organisms 19: 233237.

Eboigbodin KE, JJ Ojeda \& CA Biggs. 2007. Investigating the surface properties of Escherichia coli under glucose controlled conditions and its effect on aggregation. Langmuir 23(12): 6691-6697.

Eiler A, C Gonzalez-Rey, S Allen \& S Bertilsson. 2007. Growth response of Vibrio cholerae and other Vibrio spp. to cyanobacterial dissolved organic matter and temperature in brackish water. FEMS (Federation of European Microbiological Societies) Microbiology Ecology 60(3): 411-418.

Eiler A, M Johansson \& S Bertilsson. 2006. Environmental influences on Vibrio populations in Northern temperate and boreal coastal waters (Baltic and Skagerrak Seas). Applied and Environmental Microbiology 72(9): 6004-6011.

Eilers H, J Pernthaler \& R Amann. 2000. Succession of pelagic marine bacteria during enrichment: a close look at cultivation-induced shifts. Applied and Environmental Microbiology 66: 4634-4640.

Elston R, EL Elliot \& RR Colwell. 1982. Conchiolin infection and surface coating Vibrio: shell fragility, growth depression and mortalities in cultured oysters and clams, Crassostrea virginica, Ostrea edulis and Mercenaria mercenaria. Journal of Fish Diseases 5: 265-284.

Elston RA, L Leibovitz, D Relyea \& J Zatila. 1981. Diagnosis of vibriosis in a commercial oyster hatchery epizootic: diagnostic tools and management features. Aquaculture 24: 53-62.

Enger O, B Husevag \& J Goksoyr. 1991. Seasonal variation in presence of Vibrio salmonicida and total bacterial counts in
Norwegian fish-farm water. Canadian Journal of Microbiology 37(8): 618-623.

Estes RM, CS Friedman, RA EIston \& RP Herwig. 2004. Pathogenicity testing of shellfish hatchery bacterial isolates on Pacific oyster Crassostrea gigas larvae. Diseases of Aquatic Organisms 58(2-3): 223-230.

Esteve C. 1995. Numerical taxonomy of Aeromonadaceae and Vibrionaceae associated with reared fish and surrounding fresh and brackish water. Systematic and Applied Microbiology 18: 391-402.

Farmer JJ \& FW Hickman-Brenner. 2006. The genera Vibrio and Photobacterium. En: Dworkin M, S Falkow, E Rosenberg, K Schleifer \& E Stackebrandt (eds), The Prokaryotes: an Evolving Electronic Resource for the Microbiological Community, $3^{\text {rd }}$ ed., release 3.7. SpringerVerlag, Nueva York.

Fidopiastis PM, SV Boletzky \& EG Ruby. 1998. A new niche for Vibrio logei, the predominant light organ symbiont of squids in the genus Sepiola. Journal of Bacteriology 180: 59-64.

Flye-Sainte MJ, S Pouvreau, C Paillard \& F Jean. 2007. Impact of Brown Ring Disease on the energy budget of the Manila clam Ruditapes philippinarum. Journal of Experimental Marine Biology and Ecology 349: 378-389.

Fouz BI, JL Larsen \& AE Toranzo. 1991. Vibrio damsela as a pathogenic agent causing mortalities in cultured turbot (Scophthalmus maximus). Bulletin of the European Association of Fish Pathologists 11: 80-81.

Garcia T, K Otto, S Kjelleberg \& DR Nelson. 1997. Growth of Vibrio anguillarum in salmon intestinal mucus. Applied and Environmental Microbiology 63(3): 1034-1039.

Garland CD, GV Nash, CE Sumner \& AM McMeekin. 1983. Bacterial pathogens of oyster larvae (Crassostrea gigas) in a Tasmanian hatchery. Australian Journal of Marine and Freshwater Research 34: 483-487.

Garriques D \& GArévalo. 1995. An Evaluation of the production and use of a live bacterial isolate to manipulate the microbial flora in the commercial production of Penaeus vannamei postlarvae in Ecuador. En: Browdy C \& J Hopkins (eds), Swimming Through Troubled Water, pp. 53-59. Proceedings of the Special Session on Prawn Farming, Aquaculture'95. World Aquaculture Society, Baton Rouge.

Goarant C, J Herlin, R Brizard, AL Marteau, C Martin \& B Martin. 2000. Toxic factors of Vibrio strains pathogenic to shrimp. Diseases of Aquatic Organisms 40: 101-107.

Gomez-Gil B, FL Thompson, CC Thompson, A GarciaGasca, A Roque \& J Swings. 2004. Vibrio hispanicus sp. nov., isolated from Artemia sp. and sea water in Spain. International Journal of Systematic and Evolutionary Microbiology 54: 261-265.

Gomez-Gil B, FL Thompson, CC Thompson \& J Swings. 2003. Vibrio rotiferianus sp. nov., isolated from cultures of the rotifer Brachionus plicatilis. International Journal of Systematic and Evolutionary Microbiology 53: 239-243.

Gomez-Gil B, A Rogue \& G Velasco-Blanco. 2002. Culture of 
Vibrio alginolyticus $\mathrm{C} 7 \mathrm{~b}$, a potential probiotic bacterium, with the microalga Chaetoceros muelleri. Aquaculture 211: 43-48.

Gomez-Gil B, A Roque \& J Turnbull. 2000. The use and selection of probiotic bacteria for use in the culture of larval aquatic organisms. Aquaculture 191: 259-270.

Gomez-Gil B, A Roque, JF Turnbull \& L Tron-Mayen. 1998. Species of Vibrio isolated from hepatopancreas, haemolymph and digestive tract of a population of healthy juvenile Penaeus vannamei. Aquaculture 163: 1-9.

Gomez-Leon J, L Villamil, ML Lemos, B Novoa \& A Figueras. 2005. Isolation of Vibrio alginolyticus and Vibrio splendidus from aquacultured carpet shell clam (Ruditapes decussatus) larvae associated with mass mortalities. Applied and Environmental Microbiology 71: 98-104.

Grischowsky RS \& L Liston. 1974. Bacterial pathogenicity in laboratory-induced mortality of the pacific oyster (Crassostrea gigas Thunberg). Proceedings of the National Shellfisheries Association 64: 82-91.

Gullian M, F Thompson \& J Rodriguez. 2004. Selection of probiotic bacteria and study of their immunostimulatory effect in Penaeus vannamei. Aquaculture 233: 1-14.

Haines K \& RL Guillard. 1974. Growth of vitamin B12 requiring marine diatoms in mixed laboratory cultures with vitamin B12 producing marine bacteria. Journal of Phycology 10: 245-252.

Heidelberg JF, KB Heidelberg \& RR Colwell. 2002. Bacteria of the gamma-subclass Proteobacteria associated with zooplankton in Chesapeake Bay. Applied and Environmental Microbiology 68: 5498-5507.

Henke JM \& BL Bassler. 2004. Quorum sensing regulates type III secretion in Vibrio harveyi and Vibrio parahaemolyticus. Journal of Bacteriology 186: 3794-3805.

Herbert RA. 1999. Nitrogen cycling in coastal marine ecosystems. FEMS Microbiology Review 23: 563-590.

Hernández C, J Ulloa, JÁ Vergara, R Espejo \& F Cabello. 2005. Infecciones por Vibrio parahaemolyticus e intoxicaciones por algas: problemas emergentes de salud pública en Chile. Revista Médica de Chile 133: 1081-1088.

Hjelm M, A Riaza, F Formoso, J Melchiorsen \& L Gram. 2004. Seasonal incidence of autochthonous antagonistic Roseobacter spp. and Vibrionaceae strains in a turbot larva (Scophthalmus maximus) rearing system. Applied and Environmental Microbiology 70 (12): 7288-7294.

Irianto A \& B Austin. 2003. Use of dead probiotic cells to control furunculosis in rainbow trout, Oncorhynchus mykiss (Walbaum). Journal of Fish Diseases 26: 59-62.

Ishimaru K, M Akagawa-Matsushita \& K Muroga. 1996. Vibrio ichthyoenteri sp. Nov., a pathogen of Japanese flounder (Paralichthys olivaceus). Interntional journal of Systematic Bacteriology 46: 155-159.

Jayasree L, P Janakiram \& R Madhav. 2006. Characterization of Vibrio spp. associated with diseased shrimp from culture Ponds of Andhra Pradesh (India). Journal of the World Aquaculture Society 37(4): 523-532.
Jeffries VE. 1982. Three Vibrio strains pathogenic to larvae of Crassostrea gigas and Ostrea edulis. Aquaculture 1982: 201-226.

Ji RX, Zou WZ, Hu SL \& QP Yan. 2008. Vaccination in three different ways against vibriosis of Seriola dumerili caused by Vibrio hollisae. Chinese Journal of Oceanology and Limnology 26 (3): 233-237.

Jiang SC. 2001. Vibrio cholerae in recreational beach waters and tributaries of Southern California. Hydrobiology 460: 157-164.

Jorquera MA, CE Riquelme, LA Loyola \& LF Muñoz. 1999. Production of bactericidal substances by a marine vibrio isolated from cultures of the scallop Argopecten purpuratus. Aquaculture International 7: 433-448.

Kamei Y, M Yoshimizu, Y Ezura \& T Kimura. 1988. Screening of bacteria with antiviral activity from fresh water salmonid hatcheries. Microbiology and Immunology 32(1): 67-73.

Kaysner CA \& A DePaola. 2000. Outbreaks of Vibrio parahaemolyticus gastroenteritis from raw oyster consumption: assessing the risk of consumption and genetic methods for detection of pathogenic strains. Journal of Shellfish Research 19(1): 657.

Konaklieva MI \& BJ Plotkin. 2006. Chemical communication - Do we have a quorum? Mini-Reviews in Medicinal Chemistry 6(7): 817-825.

Kushmaro A, E Banin, Y Loya, E Stackebrandt \& E Rosenberg. 2001. Vibrio shiloi sp. nov., the causative agent of bleaching of the coral Oculina patagonica. International Journal of Systematic and Evolutionary Microbiology 51: 1383-1388.

Koren O \& E Rosenberg. 2006. Bacteria Associated with mucus and tissues of the coral Oculina patagonica in summer and winter. Applied and Environmental Microbiology 72(8): 5254-5259.

Lambert C, JL Nicolas \& V Bultel. 2001. Toxicity to bivalve hemocyte of pathogenic Vibrio cytoplasmic extract. Journal of Invertebrate Pathology 77: 165-172.

Lambert C, JL Nicolas \& V Cilia. 1999. Vibrio splendidusrelated strain isolated from brown deposit in scallop (Pecten maximus) cultured in Brittany (France). Bulletin of the European Association of Fish Pathologists 19: 102-106.

Lamas J, R Anadon, S Devesa \& AE Toranzo. 1990. Visceral neoplasia and epidermal papillomas in cultured turbot Scophthalmus maximus. Diseases of Aquatic Organisms 8: 179-187.

Lavilla-Pitogo CR \& DL Dela Pena. 1998. Mortalities of pondcultured juvenile shrimp, Penaeus monodon, associated with dominance of luminescent vibrios in the rearing environment. Aquaculture 164: 337-349.

Lavilla-Pitogo C, M Baticados, E Cruz-Lacierda \& L Dela Peña. 1990. Occurrence of luminous bacterial disease of Penaeus monodon larvae in the Philippines. Aquaculture 91: 1-13. 
Lenz DH \& BL Bassler. 2007. The small nucleoid protein Fis is involved in Vibrio cholerae quorum sensing. Molecular Microbiology 63(3): 859-871.

Le Roux F, M Gay, C Lambert, JL Nicolas, M Gouy \& F Berthe. 2004. Phylognetic study and identification of Vibrio splendidus related strains based on GyrB gene sequences. Diseases of Aquatic Organisms 58:143-150.

Li X \& S Rosemam. 2004. The chitinolytic cascade in vibrios is regulated by chitin oligosaccharides and a two-component chitin catabolic sensor/kinase. Proceedings of the National Academy of Sciences of the United States of America 101: 627-631.

Lilley BN \& BL Bassler. 2000. Regulation of quorum sensing in Vibrio harveyi by LuxO and sigma-54. Molecular Microbiology 36: 940-954.

Lipp EK, ING Rivera, AI Gil, EM Espeland, N Choopun \& VR Louis. 2003. Direct detection of Vibrio cholerae and ctxA in Peruvian coastal water and plankton by PCR. Applied and Environmental Microbiology 69: 3676-3680.

Lipp EK, A Huq \& RR Colwell. 2002. Effects of global climate on infectious disease: the cholera model. Clinical Microbiology Reviews 15: 757-770.

Lodeiros C, J Bolinches, CP Dopazo \& AE Toranzo. 1987. Bacillary necrosis in hatcheries of Ostrea edulis in Spain. Aquaculture 65: 15-29.

Long RA \& F Azam. 2001. Antagonistic interactions among marine pelagic bacteria. Applied and Environmental Microbiology 67: 4975-4983.

Luna-Gonzales A, AN Maeda-Martinez, JC Sainz \& F Ascencio-Valle. 2002. Comparative susceptibility of veliger larvae of four bivalve mollusks to a Vibrio alginolyticus strain. Diseases of Aquatic Organisms 49: 221-226.

Lunder T, H Sorum, G Holstad, AG Steigerwalt, P Mowinckel \& DJ Brenner. 2000. Phenotypic and genotypic characterization of Vibrio viscosus sp. nov. and Vibrio wodanis sp. nov. isolated from Atlantic salmon (Salmo salar) with 'winter ulcer'. International Journal of Systematic Bacteriology 50: 427-450.

Maeda T, Y Matsuo, M Furushita \& T Shiba. 2003. Seasonal dynamics in a coastal Vibrio community examined by a rapid clustering method based on $16 \mathrm{~S}$ rDNA. Fisheries Science 69: 385-394.

Makemson JC, N Fulayfil \& P Basson. 1992. Association of luminous bacteria with artificial and natural surfaces in Arabian Gulf seawater. Applied and Environmental Microbiology 58: 2341-2343.

Maric S \& J Vranes. 2007. Characteristics and significance of microbial biofilm formation. Periodicum Biologorum 109(2): 115-121.

McDougald D, SA Rice \& S Kjelleberg. 2000. The marine pathogen Vibrio vulnificus encodes a putative homologue of the Vibrio harveyi regulatory gene, luxR: a genetic and phylogenetic comparison. Gene 248: 213-221.

Meibom KL, XB Li, AT Nielsen, CY Wu, S Roseman \& GK Schoolnik. 2004. The Vibrio cholerae chitin utilization program. Proceedings of the National Academy of Sciences of the United States of America 101: 2524-2529.

Milton D, LA Hardman, M Camara, SR Chhabra, BW Bycroft, GS Stewart \& P Williams. 1997. Quorum sensing in Vibrio anguillarum: characterization of the vanI/vanR locus and identification of the autoinducer $N$-(3oxodecanoyl)-L-homoserine lactone. Journal of Bacteriology 179: 3004-3012.

Molina-Aja A, A Garcia-Gasca, A Abreu-Grobois, C BolanMejia, A Roque \& B Gomez-Gil. 2002. Plasmid profiling and antibiotic resistance of Vibrio strains isolated from cultured penaeid shrimp. FEMS Microbiology Letters 213: 7-12.

Moss SM, BR LeaMaster \& JN Sweeney. 2000. Relative abundance and species composition of gram-negative, aerobic bacteria associated with the gut of juvenile white shrimp Litopenaeus vannamei reared in oligotrophic well water and eutrophic pond water. Journal of the World Aquaculture Society 31: 255-263.

Muroga K, H Yasunobu, N Okada \& K Masumura. 1990. Bacterial enteritis of cultured flounder Paralichthys olivaceus larvae. Diseases of Aquatic Organisms 9: 121125.

Naviner M, JP Bergé, P Durand \& H Le Bris. 1999. Antibacterial activity of marine diatom Skeletonema costatum against aquacultural pathogens. Aquaculture 174: 15-24.

Nichols DS. 2003. Prokaryotes and the input of polyunsaturated fatty acids to the marine food web. FEMS Microbiology Letters 219: 1-7.

Nicolas JL, O Basuyaux, J Mazurie \& A Thebault. 2002. Vibrio carchariae, a pathogen of the abalone Haliotis tuberculata. Diseases of Aquatic Organisms 50: 35-43.

Nishibuchi M. 2006. Molecular identification. The biology of vibrios, 4: 44-64. ASM Press, Washington DC.

Nishiguchi MK. 2000. Temperature affects species distribution in symbiotic populations of Vibrio spp. Applied and Environmental Microbiology 66: 3550-3555.

Nogi Y, N Masui \& C Kato. 1998. Photobacterium profundum sp. nov., a new, moderately barophilic bacterial species isolated from a deep-sea sediment. Extremophiles 2: 1-7.

Novoa B, A Luque, D Castro, JJ Borrego \& A Figueras. 1998. Characterization and infectivity of four bacterial strains isolated from brown ring disease-affected clams. Journal of Invertebrate Pathology 71: 34-41.

Ohara S, K Fukami \& Y Ishida. 1993. Algal effects on the bacterial assemblage in Lake Biwa. Japanese Journal of Limnology 54: 261-268.

Olafsen JA. 2001. Interactions between fish larvae and bacteria in marine aquaculture. Aquaculture 200: 223-247.

Olsen AI, Y Olsen, Y Attramadal, K Christie, TH Birkbeck, J Skjermo \& O Vadstein. 2000. Effects of short term feeding of microalgae on the bacterial flora associated with juvenile Artemia franciscana. Aquaculture 190: 11-25. 
Oxley AP, W Shipton, L Owens \& D McKay. 2002. Bacterial flora from the gut of the wild and cultured banana prawn, Penaeus merguiensis. Journal of Applied Microbiology 93: 214-223.

Pacini F. 1854. Osservazioni microscopiche e deduzione patologiche sul colera asiatico. Gazette Medicale de Italiana Toscano Firenze 6: 405-412.

Paillard C, F Le Roux \& JJ Borrego. 2004. Bacterial disease in marine bivalves, a review of recent studies: trends and evolution. Aquatic Living Resources 17: 477-498.

Paillard C \& P Maes. 1995. The Brown Ring Disease in the Manila clam, Ruditapes philippinarum. I. Ultrastructural alterations of the periostracal lamina. Journal of Invertebrate Pathology 65: 91-100.

Platt MR, MD Rich \& JC Mclaughlin. 1995. The role of chitin in the thermoprotection of Vibrio cholerae. Journal of Food Protection 58(5): 513-514.

Pujalte MJ, M Ortigosa, MC Macián \& E Garay. 1999. Aerobic and facultative anaerobic heterotrophic bacteria associated to Mediterranean oysters and seawater. International Microbiology 2: 259-266.

Radjasa OK, H Urakawa, K Kita-Tsukamoto \& K Ohwada. 2001. Characterization of psychrotrophic bacteria in the surface and deep-sea waters from the northwestern Pacific Ocean based on $16 \mathrm{~S}$ ribosomal DNA analysis. Marine Biotechnology 3: 454-462.

Ramesh A, B Loganathan \& V Venugopalan. 1989. Seasonal distribution of luminous bacteria in the sediments of a tropical estuary. Journal of General and Applied Microbiology 35: 363-368.

Ransom DP, CN Lannan, JS Rohovec \& JL Fryer. 1984. Comparison of histopathology caused by Vibrio anguillarum and Vibrio ordalii in three species of Pacific salmon. Journal of Fish Diseases 7: 107-115.

Reay DS, DB Nedwell, J Priddle \& JC Ellis-Evans. 1999. Temperature dependence of inorganic nitrogen uptake: reduced affinity for nitrate at suboptimal temperatures in both algae and bacteria. Applied and Environmental Microbiology 65: 2577-2584.

Reddacliff GL, M Hornitsky, J Carson, R Petersen \& R Zelski. 1993. Mortalities of goldfish, Carassius auratus (L.), associated with Vibrio cholerae (non-O1). Journal of Fish Diseases 16: 517-520.

Redfield RJ. 2002. Is quorum sensing a side effect of diffusion sensing? Trends in Microbiology 10: 365-370.

Reynaud Y, D Saulnier, D Mazel, C Goarant \& F Le Roux. 2008. Correlation between detection of a plasmid and highlevel virulence of Vibrio nigripulchritudo, a pathogen of the shrimp Litopenaeus stylirostris. Applied and Environmental Microbiology 74(10): 3038-3047.

Rico-Mora R \& D Voltolina. 1995. Effects of bacterial isolates from Skeletonema costatum cultures on the survival of Artemia franciscana nauplii. Journal of Invertebrate Pathology 66 (2): 203-204.
Riemann L \& F Azam. 2002. Widespread $N$-acetyl-Dglucosamine uptake among pelagic marine bacteria and its ecological implications. Applied and Environmental Microbiology 68: 5554-5562.

Riquelme C, R Araya \& R Escribano. 2000. Selective incorporation of bacteria by Argopecten purpuratus larvae: implications for the use of probiotics in culturing systems of the Chilean scallop. Aquaculture 181: 25-36.

Riquelme C, R Araya, N Vergara, A Rojas, N Guaita \& M Candia. 1997. Potential probiotic strains in the culture of the Chilean scallop Argopecten purpuratus (Lamarck, 1819). Aquaculture 154: 17-26.

Riquelme C, G Hayashida, AE Toranzo, J Vilches \& P Chavez. 1995. Pathogenicity studies on a Vibrio anguillarum-related (VAR) strain causing an epizootic in Argopecten purpuratus larvae cultured in Chile. Diseases of Aquatic Organisms 22: 135-141.

Riquelme CE \& R Avendaño-Herrera. 2003. Interacción bacteria-microalga en el ambiente marino y uso potencial en acuicultura. Revista Chilena de Historia Natural 76: 725 736.

Riquelme CE, MA Jorquera, AI Rojas, RE Avendaño \& N Reyes. 2001. Addition of inhibitor-producing bacteria to mass cultures of Argopecten purpuratus larvae (Lamarck, 1819). Aquaculture 192: 111-119.

Riquelme CE \& Y Ishida. 1988. Chemotaxis of bacteria to extracellular products of marine bloom algae. Journal of General and Applied Microbiology 34(5): 417-423.

Rosenberg E \& O Koren. 2006. Vibrios in coral health and disease. The biology of vibrios, 16: 231-238. ASM Press, Washington DC.

Rosenberg E \& Y Ben-Haim. 2002. Microbial diseases of corals and global warming. Environment Microbiology 4: 318-326.

Rowe-Magnus DA, M Zouine \& D Mazel. 2006. The adaptive genetic arsenal of pathogenic vibrio species: the role of integrons. The biology of vibrios 8: 95-111. ASM Press, Washington DC.

Saeed MO, MM Alamoudi \& AH Al-Harbi. 1987. A Pseudomonas associated with disease in cultured rabbitfish Siganus rivulatus in the Red Sea. Diseases of Aquatic Organisms 3: 177-180.

Sawabe T. 2006. The mutual partnership between Vibrio halioticoli and abalones. The biology of vibrios, 15: 219230. ASM Press, Washington DC.

Sawabe T, N Setogushi, S Inoue, R Tanaka, M Ootsubo, M Yoshimizu \& Y Ezura. 2003. Acetic acid production of Vibrio halioticoli from alginate: a possible role for establishment of abalone - $V$. halioticoli association. Aquaculture 219: 671-679.

Sawabe T, Y Oda, Y Shiomi \& Y Ezura Y. 1995. Alginate degradation by bacteria isolated from the gut of sea urchins and abalones. Microbial Ecology 30: 192-202.

Simidu U \& K Tsukamoto. 1985. Habitat segregation and biochemical activities of marine members of the family 
Vibrionaceae. Applied and Environmental Microbiology 50: 781-790.

Snoussi M, K Chaieb, Mahmoud \& A Bakhrouf. 2006. Quantitative study, identification and antibiotics sensitivity of some Vibrionaceae associated to a marine fish hatchery. Annals of Microbiology 56(4): 289-293.

Sotomayor MA \& JL Balcázar. 2003. Inhibición de vibrios patógenos de camarón por mezclas de cepas probióticas. Revista AquaTIC 19: 9-15.

Suantika G, P Dhert, G Rombaut, J Vanderberghe, T De Wolf \& P Sorgeloos. 2001. The use of ozone in a high density recirculation system for rotifers. Aquaculture 201: 35-49.

Sudheesh PS \& HS Xu. 2001. Pathogenicity of Vibrio parahaemolyticus in tiger prawn Penaeus monodon Fabricius: possible role of extracellular proteases. Aquaculture 196: 37-46.

Suginta W, A Vongsuwan, C Songsiriritthigul, H Prinz, P Estibeiro, RR Duncan, J Svasti \& LA Fothergill-Gilmore. 2004. An endochitinase A from Vibrio carchariae: cloning, expression, mass and sequence analyses, and chitin hydrolysis. Archives of Biochemistry and Biophysics 424: 171-180.

Sugita H, Y Hirose, N Matsuo \& Y Deguchi. 1998. Production of the antibacterial substance by Bacillus sp. strain NM 12, an intestinal bacterium of Japanese coastal fish. Aquaculture 165: 269-280.

Sugita H, K Shibuya, H Hanada \& Y Deguchi. 1997. Antibacterial abilities of intestinal microbiota of the river fish. Fisheries Science 63(3): 379-383.

Takahashi KG, A Nakamura \& K Mori. 2000. Inhibitory effects of ovoglobulins on bacillary necrosis in larvae of the Pacific oyster, Crassostrea gigas. Journal of Invertebrate Pathology 75: 212-217.

Takahashi Y, T Itami T, M Maeda \& M Kondo. 1998. Bacterial and viral diseases of Kuruma shrimp (Penaeus japonicus) in Japan. Fish Pathology 33: 357-364.

Tamplin ML, A Gauzens, A Huq, DA Sack \& RR Colwell. 1990. Attachment of Vibrio cholerae serogroup $\mathrm{O} 1$ to Zooplankton and Phytoplankton of Bangladesh waters. Applied and Environmental Microbiology 56(6): 19771980.

Tendencia EA \& M Dela Peña. 2003. Investigation of some component of green water system which makes it effective in the initial control of luminous bacteria. Aquaculture 218: 115-119.

Thompson FL \& J Swings. 2006. Taxonomy of the vibrios. The biology of vibrios, 3: 29-43. ASM Press, Washington DC.

Thompson FL, D Gevers, CC Thompson, P Dawyndt, S Naser, B Hoste, CB Munn \& J Swings. 2005. Phylogeny and molecular identification of vibrios on the basis of multilocus sequence analysis. Applied and Environmental Microbiology 71: 5107-5115.

Thompson JR \& MF Polz. 2006. Dynamics of Vibrio populations and their role in environmental nutrient cycling.
The biology of vibrios, 13: 190-203. ASM Press, Washington DC.

Thompson JR, MA Randa, LA Marcelino, A TomitaMitchell, E Lim \& MF Polz. 2004. Diversity and dynamics of a North Atlantic coastal Vibrio community. Applied and Environmental Microbiology 70: 4103-4110.

Tison DL, M Nishibuchi, JD Greenwood \& RJ Seidler. 1982. Vibrio vulnificus biogroup 2: a new biogroup pathogenic for eels. Applied and Environmental Microbiology 44: 640646.

Toranzo A, B Magariños \& J Romalde. 2005. A review of the main bacterial fish diseases in mariculture systems. Aquaculture 246: 37-61.

Toranzo AE \& JL Barja. 1990. A review of the taxonomy and seroepizootiology of Vibrio anguillarum, with special reference to aquaculture in the northwest of Spain. Diseases of Aquatic Organisms 9: 73-82.

Toranzo AE \& JL Barja. 1993. Virulence factors of bacteria pathogenic for cold water fish. Annual Review of Fish Diseases 3: 5-36.

Tubiash HS, RR Colwell \& R Sakazaki. 1970. Marine vibrios associated with bacillary necrosis, a disease of larval and juvenile bivalve mollusks. Journal of Bacteriology 103: 272-273.

Tubiash HS, PE Chanley \& E Leifson. 1965. Bacillary necrosis disease of larval and juvenile bivalve molluses. I. Etiology and epizootiology. Journal of Bacteriology 90: 1036-1044.

Urakawa H \& IN Rivera. 2006. Aquatic environment. The biology of vibrios, 12: 175-189. ASM Press, Washington DC.

Urbanczyk H, JC Ast, MJ Higgins, J Carson \& PV Dunlap. 2007. Reclassification of Vibrio fischeri, Vibrio logei, Vibrio salmonicida and Vibrio wodanis as Aliivibrio fischeri gen. nov., comb. nov., Aliivibrio logei comb. nov., Aliivibrio salmonicida comb. nov. and Aliivibrio wodanis comb. nov. International Journal of Systematic and Evolutionary Microbiology 57: 2823-2829.

Urdaci MC, LJ Stal \& M Marchand. 1988. Occurrence of nitrogen fixation among Vibrio spp. Archives of Microbiology 224-229.

Van HR, M Givskov \& CW Michiels. 2007. Quorum sensing in Serratia. FEMS Microbiology Reviews 31(4): 407-424.

Verschuere L, G Rombaut, P Sorgeloos \& W Verstraete. 2000a. Probiotic bacteria as biological control agents in aquaculture. Microbiology and Molecular Biology Review 64: 655-671.

Verschuere L, H Heang, G Criel, P Sorgeloos \& W Verstraete. 2000b. Selected bacterial strains protect Artemia spp. from the pathogenic effects of Vibrio proteolyticus CW8T2. Applied and Environmental Microbiology 66: 1139-1146.

Waechter Mä, F Le Roux, J Nicolas, E Marissal \& F Berthe. 2002. Caractérisation de bactéries pathogènes de naissain 
d'huître creuse Crassostrea gigas. Comptes Rendus Biologies 325(3): 231-238.

Watnick PL, CM Lauriano, KE Klose, L Croal \& R Kolter. 2001. The absence of a flagellum leads to altered colony morphology, biofilm development and virulence in Vibrio cholerae O139. Molecular Microbiology 39: 223-235.

Wolfe AJ, DS Millikan, JM Campbell \& KL Visick. 2004. Vibrio fischeri sigma (54) controls motility, biofilm formation, luminescence, and colonization. Applied and Environmental Microbiology 70: 2520-2524.

Worden AZ, M Seidel, S Smriga, A Wick, F Malfatti, D Bartlett \& F Azam. 2006. Trophic regulation of Vibrio cholerae in coastal marine waters. Environmental Microbiology 8: 21-29.
Yamanoi H, K Muroga \& S Takahashi. 1980. Physiological characteristics and pathogenicity of NAG vibrio isolated from diseased ayu. Fish Pathology 15: 69-73.

Yoshinaga I, T Kawai \& Y Ishida. 1997. Analysis of algicidal ranges of the bacteria killing the marine dinoflagellate Gymnodinium mikimotoi isolated from Tanabe Bay, Wakayama Pref., Japan. Fisheries Science 63: 94-98.

Zorrilla I, M Chabrillón, S Arijo, P Diaz-Rosales, E Martinez-Manzanares, MC Balebona \& MA Moriñigo. 2003. Bacteria recovered from diseased cultured gilthead sea bream (Sparus aurata L.) in southwestern Spain. Aquaculture 218: 11-20.

Zhu J \& JJ Mekalanos. 2003. Quorum sensing-dependent biofilms enhance colonization in Vibrio cholerae. Developmental Cell 5: 647-656.

Recibido el 7 de octubre de 2008 y aceptado el 21 de octubre de 2008 